in vivo $35: 3431-3439(2021)$

doi:10.21873/invivo.12643

\title{
Comparison of Three Assays for Total and Free PSA Using Hybritech and WHO Calibrations
}

\author{
MANUEL M. GARRIDO ${ }^{1,2}$, JOSÉ C. MARTA ${ }^{1}$, RUY M. RIBEIRO $^{3}$, \\ LUÍS C. PINHEIRO ${ }^{4,5}$, STEFAN HOLDENRIEDER $^{6}$ and JOÃO T. GUIMARÃES $7,8,9$ \\ ${ }^{1}$ Department of Clinical Pathology, Centro Hospitalar Universitário de Lisboa Central, Lisbon, Portugal; \\ ${ }^{2}$ Department of Laboratory Medicine, Faculdade de Medicina da Universidade de Lisboa, Lisbon, Portugal; \\ ${ }^{3}$ Biomathematics Laboratory, Faculdade de Medicina da Universidade de Lisboa, Lisbon, Portugal; \\ ${ }^{4}$ Department of Urology, Centro Hospitalar Universitário de Lisboa Central, Lisbon, Portugal; \\ ${ }^{5}$ Department of Urology, Faculdade de Ciências Médicas da Universidade Nova de Lisboa, Lisbon, Portugal; \\ ${ }^{6}$ Institute of Laboratory Medicine, Munich Biomarker Research Center, \\ Deutsches Herzzentrum München, Technische Universität München, Munich, Germany; \\ ${ }^{7}$ Department of Clinical Pathology, Centro Hospitalar Universitário de São João, Porto, Portugal; \\ ${ }^{8}$ Department of Biomedicine, Faculdade de Medicina, Universidade do Porto, Porto, Portugal; \\ ${ }^{9}$ EPIUnit, Instituto de Saúde Pública, Universidade do Porto, Porto, Portugal
}

\begin{abstract}
Background/Aim: Lack of interchangeability between prostate-specific antigen (PSA) assays could have a clinical impact. We compared PSA assays from different manufacturers and calibrations. Patients and Methods: A total of 233 men who underwent prostate biopsy (PSA: 2-10 ng/ml; Beckman Coulter Access ${ }^{\circledR}$ Hybritech ${ }^{\circledR}$ as reference) were enrolled. Total (tPSA) and free PSA (fPSA) were also measured using the Roche cobas ${ }^{\circledR}$ and the Abbott Architect ${ }^{\circledR}$ methods. Results: Roche tPSA values were $\approx 1 \%$ higher than Beckman, while Abbott values were $\approx 5 \%$ lower. Roche had the highest diagnostic sensitivity (92\%) compared to Beckman Coulter (87\%) and Abbott (85\%). Roche fPSA was $\approx 3 \%$ lower and Abbott $\approx 17 \%$ higher than that of Beckman. For the percentage of fPSA, Roche had the highest sensitivity (98\%). Conclusion: Roche cobas ${ }^{\circledR}$ and Beckman Coulter Access ${ }^{\circledR}$ Hybritech ${ }^{\circledR}$ tPSA were almost interchangeable. While the agreement was acceptable for TPSA, this did not happen with IPSA and greater efforts for harmonization are required.
\end{abstract}

This article is freely accessible online.

Correspondence to: Manuel M. Garrido, MD, Centro Hospitalar Universitário de Lisboa Central, Hospital de São José, Serviço de Patologia Clínica, Rua José António Serrano, 1150-199 Lisbon, Portugal. Tel: +351 218841879, e-mail: manuel.agarrido@ chlc.minsaude.pt

Key Words: Method comparison, prostate cancer, total PSA, free PSA, hybritech calibration, WHO calibration.
Serum prostate-specific antigen (PSA) has been widely used for the detection and monitoring of prostate cancer (PCa) (1, 2), since the end of 1980s (3). After the identification of PSA in 1979 (4), several immunoassays for its quantification in serum have been developed (5). Currently available commercial assays for the measurement of total PSA (tPSA) and free PSA (fPSA) are based on the immunochemical quantification of the circulating free and complexed to $\alpha 1$ antichymotrypsin forms of PSA (6-8). The free-to-total serum PSA ratio, usually given as a percentage (\%fPSA), has been proposed to differentiate benign from malignant prostate disease, improving specificity while maintaining sensitivity, especially in the diagnostic gray zone of tPSA: 4-10 ng/ml (9).

The lack of assay interchangeability could have a significant clinical impact with respect to the clinical interpretation of PSA and biopsy recommendations (10). The main reasons for assay variability were the non-equimolar detection of tPSA and the non-uniform assay calibration (11). In 1999, after the $2^{\text {nd }}$ Stanford Conference on the International Standardization of PSA assays, the World Health Organization (WHO), in order to reduce the inter-assay variability across manufacturers, developed a standard for the calibration of tPSA assays (WHO 96/670 standard), based on an equimolar ratio of 90:10 of complexed to fPSA and a separate standard for fPSA (WHO 96/668 standard) (12).

However, the multicenter studies that have been carried out to establish a clinical cut-off of $4 \mathrm{ng} / \mathrm{ml}$ for tPSA as a discriminant value to recommend prostate biopsy were not based on WHO calibrated assays. Instead, they were based on analytical methods - Tandem-R and Tandem-E - with the 
Hybritech calibration (13). Gradually, assay manufacturers have replaced their own calibrators with calibrators related to the WHO reference materials $(6,8)$. In general, the use of the WHO calibration has been reported to yield tPSA and fPSA values about $20-25 \%$ lower than those obtained with the Hybritech calibration $(14,15)$. This bias may lead to significant clinical misinterpretation and may have a clinical impact on the detection of PCa. Although this bias between different assays has been significantly reduced, several studies point out that the results are still not interchangeable for tPSA or fPSA between manufacturers (8, 16-18).

The main objective of the study was to compare three commonly used tPSA and fPSA assays from different manufacturers, and with different calibrations (Hybritech and WHO based), and to evaluate the potential clinical impact of the differences in PCa detection.

\section{Patients and Methods}

Study design and participants. In this observational study, 233 patients scheduled for prostate biopsy for suspected PCa at the Urology Department of the Central Lisbon University Hospital Center were enrolled between December 2017 and October 2019. The study, which complies with the Declaration of Helsinki, was approved by the Institution's Research Ethics Committee, and all participants provided written informed consent. All enrolled patients had a tPSA concentration between 2 and $10 \mathrm{ng} / \mathrm{ml}$ (Beckman Coulter Access ${ }^{\circledR}$ Hybritech $^{\circledR}$, which we considered as the reference PSA, i.e., the designated comparison method), and were submitted to a prostate biopsy with at least 12 cores. We chose this tPSA range not only to include the clinical cut-off of $4 \mathrm{ng} / \mathrm{ml}$, but also to encompass the tPSA range that poses most diagnostic challenges when screening and diagnosis of PCa is being made (19). The exclusion criteria were a previous history of $\mathrm{PCa}$ and factors that could affect the PSA concentration, namely, previous transurethral resection of the prostate, therapy with drugs that may affect PSA concentration (5- $\alpha$-reductase inhibitors and androgens), urinary infection contemporary to blood collection for PSA determination, and acute bacterial prostatitis in the three months prior to the biopsy. Heavily hemolyzed samples were excluded from the analysis. tPSA and fPSA concentrations were measured in all samples using assays from three different manufacturers, with different calibrations: Beckman Coulter Access ${ }^{\circledR}$ Hybritech $^{\circledR}$ (Hybritech calibrated), Abbott Architect ${ }^{\circledR}$ (WHO calibrated), and Roche cobas ${ }^{\circledR}$ (WHO calibrated).

In this study, we followed the Clinical and Laboratory Standards Institute (CLSI) guidelines for procedure comparison and bias estimation using patient samples (20).

Blood collection and analyses. For all samples, Abbott Architect ${ }^{\circledR}$ tPSA (ref. no. 7K70), and fPSA (ref. no. 7K71) were performed within $3 \mathrm{~h}$ after blood collection; \%fPSA was subsequently calculated according to the formula: (fPSA/tPSA) $\times 100$. For each sample, two $500 \mu \mathrm{L}$ aliquots were made within $4-8 \mathrm{~h}$ after blood collection and stored at $-80^{\circ} \mathrm{C}$. These aliquots were used for PSA assays using the Beckman Coulter Access ${ }^{\circledR}$ Hybritech $^{\circledR}$ (tPSA, ref. no. 37200; fPSA ref. no. 37210) and the Roche cobas ${ }^{\circledR}$ (tPSA, ref. no. 04641655; fPSA ref. no. 03289788) methods. They were thawed only once, and the measurements were performed within $4 \mathrm{~h}$ of thawing. Care was taken with storage times and temperatures, because it is well known that these are important factors in PSA stability, mostly concerning fPSA stability $(21,22)$.

The Abbott Architect ${ }^{\circledR}$ PSA determinations were made on the Architect i2000sr immunoassay system (Abbott Laboratories, Abbott Park, IL, USA), Roche cobas ${ }^{\circledR}$ PSA on the Roche cobas e411 analyzer (Roche Diagnostics, Basel, Switzerland), and Beckman Coulter Access ${ }^{\circledR}$ Hybritech $^{\circledR}$ PSA determinations on the Beckman Coulter Access 2 immunoassay analyzer (Beckman Coulter, Brea, CA, USA). Testing was performed according to the manufacturers' instructions.

Two levels of commercial quality control solutions were assayed, previously to the study samples, on each of the immunoassay analyzers (BioRad ${ }^{\circledR}$ Liquichek $^{\mathrm{TM}}$ Immunoassay Plus on the Abbott Architect i2000sr system; Roche PreciControl ${ }^{\mathrm{TM}}$ Tumor Marker on the Roche cobas e411 analyzer; Beckman Coulter Access ${ }^{\circledR} 2$ Hybritech ${ }^{\circledR}$ PSA Quality Control on the Beckman Coulter Access 2 analyzer). All values of the quality control tests were within the range of one standard deviation below or above the mean.

Statistical analysis. The Beckman Coulter Access ${ }^{\circledR}$ Hybritech ${ }^{\circledR}$ tPSA and fPSA assays, as well as the corresponding calculated $\%$ fPSA, were selected as the reference methods for statistical analysis purposes, since they used the same calibration (Hybritech) that was applied in the studies that established a clinical cutoff of 4 $\mathrm{ng} / \mathrm{ml}$ for tPSA, which corresponds to the original assay developed for tPSA, and to the first US Food and Drug Administration (FDA) approved assay for use in PCa detection $(3,13)$.

For comparison of the different methods, we used linear regression analysis and calculated the Pearson correlation coefficient $(r)$ (23). We also followed the approach proposed by Bland and Altman to analyze the agreement between the measurements using the three assays (24). We calculated the mean difference between the measurements from two manufacturers (Abbott versus Beckman Coulter and Roche versus Beckman Coulter) to estimate bias $(d)$, reported as the mean \pm standard error of the mean (SEM). The precision was defined by the limits of agreement, or the $95 \%$ confidence intervals of the bias, reported as $d \pm 1.96 s$, where $s$ is the standard deviation of the differences. We present the corresponding Bland-Altman plots.

The predictive accuracy of the biomarkers (PSA and \%fPSA) was quantified as the area under the receiver operating characteristic curve (AUC) for each of the three methods. Statistical significance was defined as a two-sided $p$-Value $<0.05$. Continuous variables were reported as mean and standard deviation (SD), if normally distributed, or as median and interquartile range (IQR) if nonnormally distributed.

Statistical analysis was performed using IBM $^{\circledR}$ SPSS ${ }^{\circledR}$ Statistics 26.0 (IBM Corp., Armonk, NY, USA, 2019). Positive and negative predictive values, as well as the Bland-Altman and linear regression plots, were calculated using MedCalc ${ }^{\circledR}$ Software version 14.8.1 (MedCalc Software Ltd., Ostend, Belgium)

\section{Results}

A total of 233 men fulfilled the inclusion criteria, of which 99.6\% ( $\mathrm{n}=232)$ were Caucasian. Overall, patients had a median age of 67.00 (IQR=61.00-72.50) years. Among the 
Garrido et al: Comparison of Three Assays for Total and Free PSA

Table I. Distribution of tPSA, fPSA and \% fPSA values for each method/manufacturer and method comparison data.

\begin{tabular}{|c|c|c|c|}
\hline & Beckman Coulter & Abbott & Roche \\
\hline \multicolumn{4}{|l|}{ tPSA } \\
\hline Mean \pm SD & $6.28 \pm 0.13$ & $5.92 \pm 0.13$ & $6.49 \pm 0.14$ \\
\hline Range & $2.06-10.07$ & $1.86-10.24$ & $2.14-10.94$ \\
\hline \multicolumn{4}{|c|}{ Linear regression analysis } \\
\hline Slope $(95 \%$ CI $)$ & & $0.95(0.91-0.98)$ & $1.01(0.99-1.04)$ \\
\hline Intercept $(95 \% \mathrm{CI})$ & & $-0.01(-0.25-0.23)$ & $0.13(-0.05-0.31)$ \\
\hline$r$ & & 0.96 & 0.98 \\
\hline \multicolumn{4}{|l|}{ Bland-Altman analysis } \\
\hline Bias $($ mean \pm SEM $)$ & & $0.36 \pm 0.04$ & $-0.22 \pm 0.03$ \\
\hline Precision $(95 \% \mathrm{CI})$ & & $-0.74,1.45$ & $-1.03,0.60$ \\
\hline \multicolumn{4}{|l|}{ fPSA } \\
\hline Median (IQR) & $0.93(0.64-1.26)$ & $0.98(0.71-1.41)$ & $0.94(0.71-1.32)$ \\
\hline Range & $0.21-3.11$ & $0.23-3.49$ & $0.26-2.48$ \\
\hline \multicolumn{4}{|c|}{ Linear regression analysis } \\
\hline Slope $(95 \% \mathrm{CI})$ & & $1.17(1.12-1.22)$ & $0.97(0.94-1.01)$ \\
\hline Intercept (95\% CI) & & $-0.03(-0.09-0.02)$ & $0.09(0.05-0.13)$ \\
\hline$r$ & & 0.95 & 0.96 \\
\hline \multicolumn{4}{|l|}{ Bland-Altman analysis } \\
\hline Bias $($ mean \pm SEM) & & $-0.14 \pm 0.01$ & $-0.06 \pm 0.01$ \\
\hline Precision $(95 \% \mathrm{CI})$ & & $-0.51,0.24$ & $-0.31,0.19$ \\
\hline \multicolumn{4}{|l|}{$\%$ fPSA } \\
\hline Median (IQR) & $15.44(11.69-19.71)$ & $18.93(13.73-24.12)$ & $16.27(12.41-20.34)$ \\
\hline Range & $4.50-40.48$ & $4.81-48.10$ & $5.03-40.86$ \\
\hline \multicolumn{4}{|c|}{ Linear regression analysis } \\
\hline Slope $(95 \%$ CI) & & $1.23(1.15-1.30)$ & $0.93(0.89-0.97)$ \\
\hline Intercept $(95 \% \mathrm{CI})$ & & $-0.21(-1.52-1.09)$ & $1.63(0.92-2.34)$ \\
\hline$r$ & & 0.95 & 0.95 \\
\hline \multicolumn{4}{|l|}{ Bland-Altman analysis } \\
\hline Bias $($ mean \pm SEM) & & $-3.50 \pm 0.26$ & $-0.42 \pm 0.13$ \\
\hline Precision $(95 \% \mathrm{CI})$ & & $-11.20,4.19$ & $-4.43,3.59$ \\
\hline
\end{tabular}

tPSA: Total prostate-specific antigen; fPSA: free prostate-specific antigen; \%fPSA: percentage of free prostate-specific antigen; SD: standard deviation; CI: confidence interval; $r$ : Pearson's correlation coefficient; SEM: standard error of the mean.

enrolled patients, $49.4 \%(n=115)$ did not have cancer on biopsy, and $50.6 \%(\mathrm{n}=118)$ were diagnosed with PCa. The median age of participants without cancer was 65.00 (IQR=60.00-71.00) years, and cases with PCa had a median age of 69.00 (IQR=62.75-73.00) years. Table I presents the distribution of tPSA, fPSA and \%PSA values obtained by the three manufacturers.

There was a good correlation between the Beckman Coulter tPSA and the other two tPSA methods, as shown by the Pearson's correlation coefficient $(r=0.96$ between Beckman and Abbott; $r=0.98$ between Beckman and Roche) (Table I). Linear regression analysis showed that the Roche tPSA assay resulted in similar levels (only $\approx 1 \%$ higher, since the intercept is close to zero) to the Beckman Coulter tPSA, while the Abbott assay results were 5\% lower (Figure 1). The Bland-Altman analysis confirmed that the differences were smaller between Beckman Coulter and Roche (Figure 2, Table I). In addition, the predictive accuracy of tPSA, evaluated by the AUC, was similar among the three manufacturers (Figure 3, Table II), since there were no significant differences between the AUC for Roche and Beckman Coulter tPSA $(p=0.268)$ and between the AUC for Abbott and Beckman Coulter $(p=0.267)$ and Abbott and Roche tPSA $(p=0.451)$.

Considering fPSA, the median was quite similar for the three methods $-0.93 \mathrm{ng} / \mathrm{ml}$ (Beckman Coulter), $0.98 \mathrm{ng} / \mathrm{ml}$ (Abbott) and $0.94 \mathrm{ng} / \mathrm{ml}$ (Roche) - being almost the same for Beckman and Roche. The Pearson's correlation coefficient was 0.95 between Beckman and Abbott and 0.96 between Beckman and Roche, respectively (Table I). The Roche fPSA assay results were approximately $3 \%$ lower than the Beckman Coulter assay, while the Abbott fPSA results were approximately $17 \%$ higher than the Beckman Coulter fPSA values. The Bland-Altman analysis (Figure 2) revealed a higher bias between Beckman Coulter and Abbott $(-0.14 \pm 0.01)$ than between Beckman Coulter and Roche $(0.06 \pm 0.01)$.

The median levels of \%fPSA were $15.44 \%$ (Beckman Coulter), $18.93 \%$ (Abbott), and 16.27\% (Roche) (Table I). 

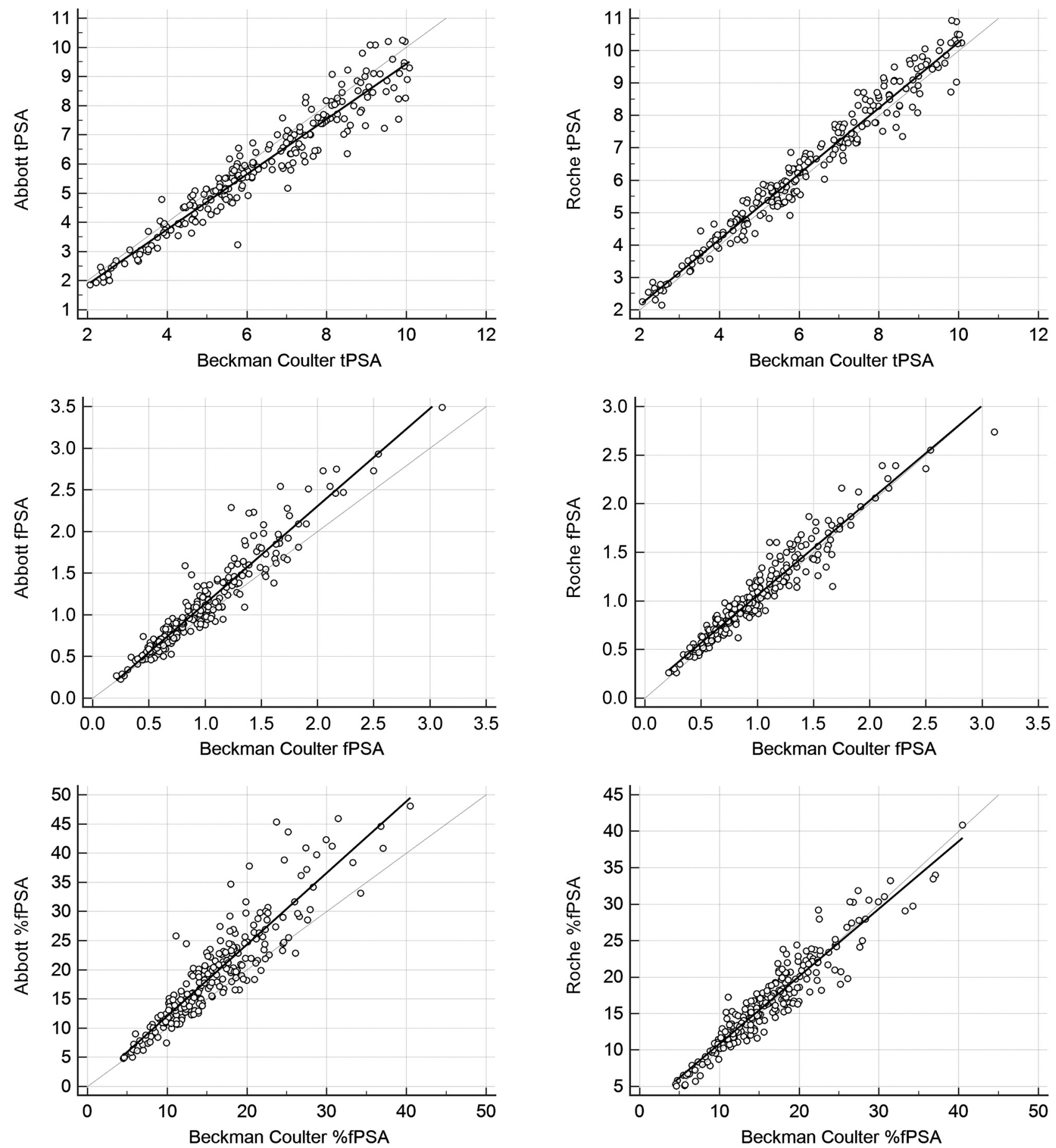

Figure 1. Linear regression analyses for Abbott and Roche tPSA, fPSA and \%fPSA values against the Beckman Coulter Access ${ }^{\circledR}$ Hybritech ${ }^{\circledR}$ method.

Although the Pearson's correlation coefficient was high $(r=0.95)$ between Beckman Coulter and both Abbott and Roche, the regression analysis showed more pronounced differences between the manufacturers. With Abbott, \%fPSA being approximately $23 \%$ higher than with Beckman Coulter (plus the 1.63 intercept value), while the Roche \%fPSA results were $7 \%$ lower than the Beckman Coulter \%fPSA results. The larger differences between Abbott and Beckman Coulter were 

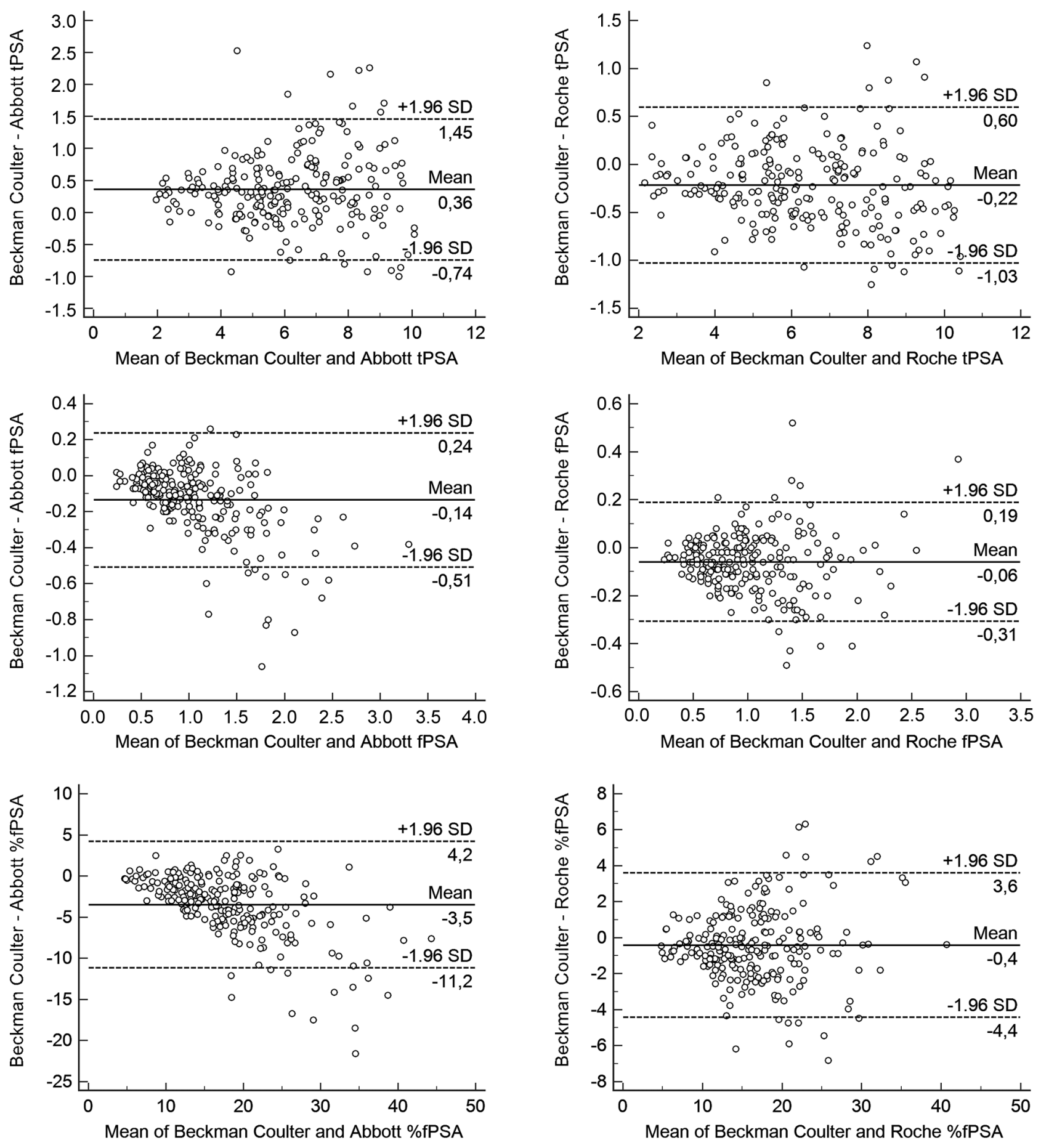

Figure 2. Bland-Altman's bias and precision plots for tPSA, fPSA and \%fPSA by the three methods.

corroborated by the Bland-Altman analysis results (Figure 2) for precision (95\% $\mathrm{CI}=-11.20-4.19)$ and bias $(-3.50 \pm 0.26)$.

The \%fPSA calculated with the tPSA and fPSA given by the three manufacturers had similar predictive accuracies, since the AUCs were similar for the three methods (Figure 3; Table II). There were no significant differences between the AUCs (Beckman versus Abbott: $p=0.814$; Beckman versus Roche: $p=0.697$; Abbott versus Roche: $p=0.548$ ). 
A

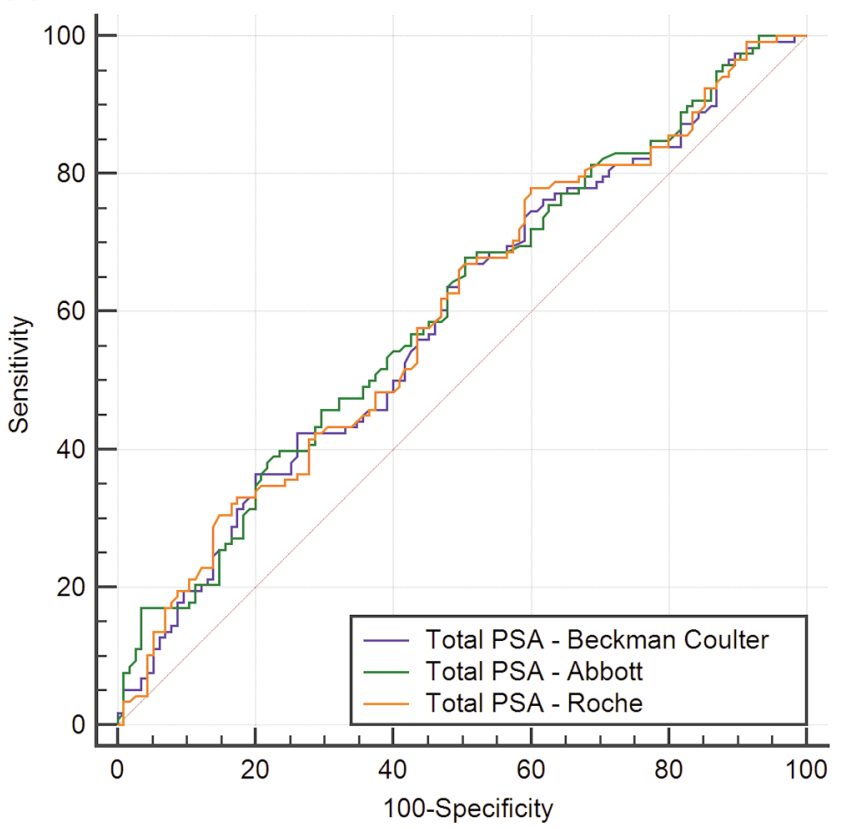

B

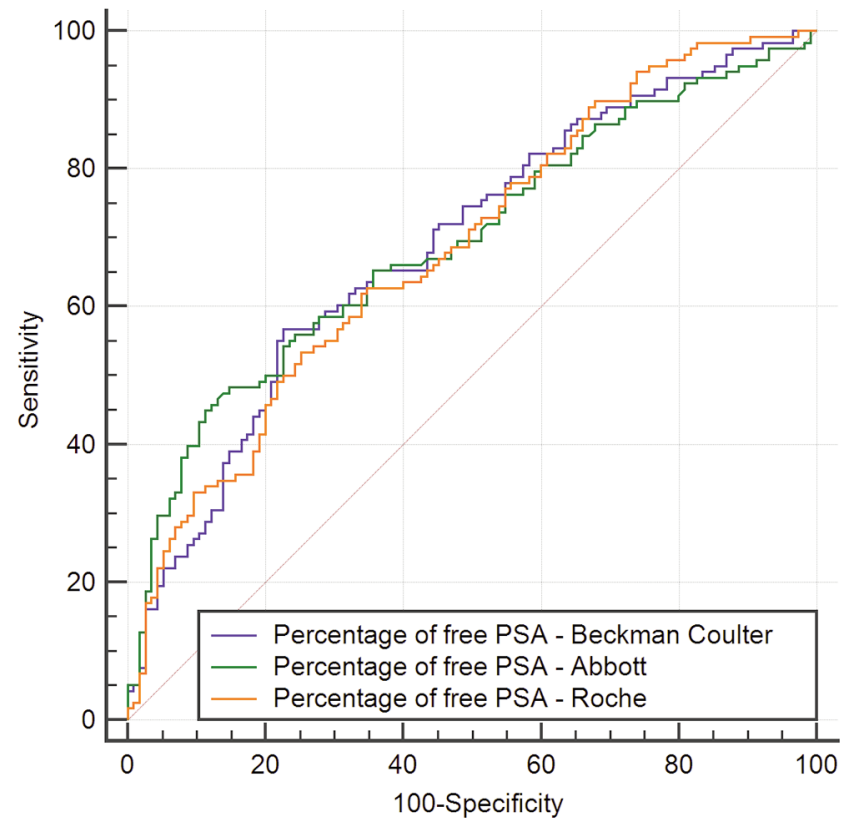

Figure 3. Receiver operating characteristic curves for: (A) Total prostate-specific antigen (PSA); (B) the percentage of free PSA, with the three methods.

\section{Discussion}

Our results show that there is a good alignment between the three evaluated tPSA assays, not only metrologically but also in terms of their clinical performance. However, this good agreement between tPSA methods is better between the Beckman Coulter Access ${ }^{\circledR}$ Hybritech ${ }^{\circledR}$ and the Roche cobas ${ }^{\circledR}$ methods than between the Beckman Coulter Access ${ }^{\circledR}$ Hybritech ${ }^{\circledR}$ and the Abbott Architect ${ }^{\circledR}$ methods. The tPSA Roche values were only approximately $1 \%$ higher than those of Beckman Coulter, while the Abbott values were approximately $5 \%$ lower. Based on the slope of the linear regression analysis, Stephan et al. also found the Roche tPSA results to be $1 \%$ higher than the Beckman Coulter Hybritech ${ }^{\circledR}$ values. These authors also verified that the Abbott tPSA values were lower than those of Beckman Coulter, although with a greater difference ( $\approx 13 \%$ lower). However, they used the older Abbott AxSYM $^{\circledR}$ PSA assay (25), while we used the more recent Abbott Architect ${ }^{\circledR}$ PSA assay. Most noticeably, the small differences that we found between the WHO-calibrated PSA assays and the Hybritechcalibrated assay are quite far from the $20-25 \%$ lower values that have been reported when comparing Beckman Coulter Hybritech ${ }^{\circledR}$ assays with Beckman Coulter WHO calibrated assays (14). Hence, we can hypothesize that the manufacturers that have calibrated their assays against the WHO 96/670 standard may have introduced factors in their calibration curves in order to promote better alignment with the Hybritech PSA. This may have been done because the first FDA-approved PSA assay was Hybritech-calibrated and because the Hybritech calibration was the one used in the large multicenter prospective study, where more than 6,600 men were evaluated to establish a worldwide accepted cutoff of $4 \mathrm{ng} / \mathrm{ml}(13,14)$.

The trend towards an improvement in the harmonization between different PSA assays can also be seen through external quality assessment (EQA) schemes. For instance, the mean coefficients of variation in the United Kingdom National External Quality Assessment Service (UK NEQAS) scheme for PSA, observed across all methods, decreased from more than $20 \%$ in 1995 to approximately $9.5 \%$ in 2005 , which also happened with other EQA providers (26-28).

The good interchangeability that we have found metrologically between the three tPSA assays reflects on similar diagnostic performances, although with some differences between them. There were no significant differences between the AUC values, in the PSA range between 2 to $10 \mathrm{ng} / \mathrm{ml}$, and the PPVs were almost the same ( $\approx 52 \%)$ for the three methods when considering the commonly used cutoff of $4 \mathrm{ng} / \mathrm{ml}$. However, when looking at diagnostic sensitivities, as well as to the NPV and the number of missed PCa, the Roche method had a slightly better clinical performance (sensitivity=92.4\%; NPV=65.38\%; missed $\mathrm{PCa}=8 \%$ ) than the Abbott method (sensitivity $=84.7 \%, \mathrm{NPV}=56.10 \%$, missed 
Garrido et al: Comparison of Three Assays for Total and Free PSA

Table II. Diagnostic performance evaluation of tPSA and \% fPSA by the three methods, considering the commonly used cutoffs.

\begin{tabular}{|c|c|c|c|}
\hline & Beckman Coulter & Abbott & Roche \\
\hline \multicolumn{4}{|l|}{ tPSA } \\
\hline AUC $(95 \% \mathrm{CI})$ & $0.592(0.519-0.665)$ & $0.603(0.531-0.675)$ & $0.597(0.524-0.669)$ \\
\hline \multicolumn{4}{|l|}{ Cut-off: $\geq 4 \mathrm{ng} / \mathrm{ml}$} \\
\hline Sensitivity, \% & 87.3 & 84.7 & 92.4 \\
\hline Specificity, \% & 16.5 & 20.9 & 14.8 \\
\hline PPV, \% (95\% CI) & $51.76 \%(49.10-54.41)$ & $52.08 \%(49.10-55.05)$ & $52.66 \%(50.36-54.95)$ \\
\hline NPV, \% (95\% CI) & $55.88 \%(40.37-70.32)$ & $56.10 \%(42.17-69.12)$ & $65.38 \%(46.75-80.25)$ \\
\hline Missed PCa, n (\%) & $15(12.7)$ & $18(15.3)$ & $9(7.6)$ \\
\hline \multicolumn{4}{|l|}{$\%$ fPSA } \\
\hline AUC & $0.690(0.622-0.757)$ & $0.694(0.626-0.761)$ & $0.684(0.617-0.752)$ \\
\hline \multicolumn{4}{|l|}{ Cut-off: $\leq 25 \%$} \\
\hline Sensitivity, \% & 94.9 & 86.4 & 98.3 \\
\hline Specificity, \% & 13.0 & 28.7 & 14.8 \\
\hline PPV, \% (95\% CI) & $52.83 \%(50.78-54.87)$ & $55.43(52.05-58.77)$ & $54.21 \%(52.22-56.18)$ \\
\hline NPV, \% (95\% CI) & $71.43 \%(50.13-86.15)$ & $67.35(54.61-77.95)$ & $89.47 \%(66.76-97.29)$ \\
\hline Missed PCa, n (\%) & $6(5.1)$ & $16(13.6)$ & $2(1.7)$ \\
\hline
\end{tabular}

tPSA: Total prostate-specific antigen; \%fPSA: percentage of free prostate-specific antigen; CI, confidence interval; AUC, area under the curve; PPV, positive predictive value; NPV, negative predictive value.

$\mathrm{PCa}=15 \%)$, or even the Beckman Coulter method (sensitivity $=87.3 \%$; NPV $=55.88 \%$; missed $\mathrm{PCa}=13 \%$ ). This shows that despite the effort of standardization brought by the WHO standards, there are still some differences between the tPSA assays. In fact, assay calibration may only be partially responsible for the differences between the assays. The interassay variability can be explained by several factors, including matrix differences between serum samples and the WHO buffer-based reference materials, which are used to assign values to the assay calibrators. Anti-PSA antibodies can have different affinities and reactivities in buffer- or in serum-based samples (29). Moreover, the use of anti-PSA antibodies with different epitope specificities and affinities for several forms of PPSA and complexed PSA has also been recognized as a cause for the lack of agreement between assays. PSA contains six major epitope regions, and it is important to know the epitopes of the antibodies used in the assays. In addition, anti-PSA antibodies can bind to human kallikrein 2 (hK2), which shares approximately $80 \%$ similarity with PSA at the amino acid level (30).

Concerning fPSA, we found larger differences between the methods, both in the linear regression and in the BlandAltman analysis, which is consistent with the results of previously published studies $(8,18,31)$. Similar to the results of the tPSA assays, the differences were more pronounced between Beckman Coulter and Abbott than between Beckman Coulter and Roche. In this respect, it is interesting to note that the Roche $\operatorname{cobas}^{\circledR}$ fPSA is standardized against the WHO 96/668 reference preparation, while the Abbott Architect ${ }^{\circledR}$ fPSA is based on the WHO 96/670 standard (8). This fact could, at least in part, explain the greater discrepancies in Abbott fPSA. The slope of Roche fPSA was only 0.97, and the slope of Abbott fPSA was 1.17 , meaning that the Roche fPSA was approximately $3 \%$ lower than the Beckman Coulter fPSA, while the Abbott fPSA was approximately $17 \%$ higher than the Beckman Coulter fPSA. Interestingly, the slope that we found between the Roche and Beckman Coulter fPSA is exactly the same as that reported by Stephan et al. (25).

When looking at the \%fPSA obtained by the three methods, the differences are even bigger than those observed with fPSA, which is also in concordance to what other authors have already reported $(18,25)$. These larger differences were shown not only by the slope and intercepts calculated through linear regression, but also by the wide limits of agreement (values of 95\% CI for precision) in Bland-Altman's analysis. Once more, the differences were more pronounced for Abbott than for Roche, when compared to Beckman Coulter.

Not surprisingly, these differences had an impact on the clinical performance of \% fPSA, when comparing the three methods. Although the values of the AUC were quite similar (between 0.684 and 0.694), Abbott had the lowest sensitivity $(86 \%)$ and Roche had the highest sensitivity (98\%), closer to Beckman Coulter's sensitivity $(95 \%)$, considering the commonly used cutoff of $25 \%$. PPVs were similar $(53 \%-$ $55 \%$ ) among the three methods, but the differences in the NPVs were larger (Abbott: 67\%; Beckman Coulter: 71\%; Roche: $89 \%$ ). The lower NPV of the Abbott \%fPSA means that a larger number of cases would be misclassified as negative for PCa. The better diagnostic performance of Roche $\%$ fPSA translated into a lower percentage of missed PCa $(\approx 2 \%)$ than that observed with Abbott $(\approx 14 \%$ of missed PCa). 
The amount of missed PCa with Beckman Coulter ( $\approx 5 \%)$ was much more similar to the value observed with Roche.

We believe that one of the main strengths of this study, is that it shows that the use of WHO-calibrated PSAs does not necessarily imply lowering the usual cut-off for recommending a prostate biopsy. Other authors had previously suggested that the usual cutoff of $4 \mathrm{ng} / \mathrm{ml}$ should be reduced to $3.1 \mathrm{ng} / \mathrm{ml}$ when PSA is measured with WHO-calibrated assays (14). Our study shows that this does not hold true for all WHO-calibrated PSA assays, namely the Roche cobas ${ }^{\circledR}$ and the Abbott Architect ${ }^{\circledR}$ assays. However, and according to studies comparing WHO- and Hybritech-calibrated PSA assays from Beckman Coulter, the observed difference of 20$25 \%$ between them could justify reducing the cut-off when using WHO-calibrated PSA from Beckman Coulter $(14,15)$. In fact, a limitation of this study is that the Beckman Coulter WHO-calibrated PSA assays were not evaluated.

In summary, despite the different calibrations (WHO versus Hybritech), within the $2-10 \mathrm{ng} / \mathrm{ml}$ PSA range, there is an acceptable agreement between the three manufacturers in terms of the tPSA assays, especially between Beckman Coulter and Roche, making these two tPSA methods almost interchangeable. For fPSA assays, the differences between methods are more significant, meaning that further harmonization efforts are required. The results of \%fPSA showed high differences between methods, with an impact on their clinical performance. Roche cobas ${ }^{\circledR}$ tPSA and fPSA assays were more aligned with the Beckman Coulter Access ${ }^{\circledR}$ Hybritech ${ }^{\circledR}$ assays than the Abbott Architect ${ }^{\circledR}$ assays. When considering the commonly used cutoffs of $4 \mathrm{ng} / \mathrm{ml}$ and $25 \%$, respectively, the Roche cobas $^{\circledR}$ tPSA and \%fPSA results had the best diagnostic performance of the three evaluated methods, with higher sensitivities, higher NPVs, and lower numbers of missed PCa.

\section{Conflicts of Interest}

The Authors declare no conflicts of interest related to this study.

\section{Authors' Contributions}

The Authors confirm their contribution to the paper as follows: study conception and design: Manuel M. Garrido; data collection: Manuel M. Garrido; analysis and interpretation of results: Manuel M. Garrido and Ruy M. Ribeiro; draft manuscript preparation: Manuel M. Garrido and José C. Marta; critical review of the manuscript: Stefan Holdenrieder, Ruy M. Ribeiro, João T. Guimarães and Luís C. Pinheiro. All Authors approved the final version of the manuscript.

\section{References}

1 Kearns JT, Holt SK, Wright JL, Lin DW, Lange PH and Gore JL: PSA screening, prostate biopsy, and treatment of prostate cancer in the years surrounding the USPSTF recommendation against prostate cancer screening. Cancer 124(13): 2733-2739, 2018. PMID: 29781117. DOI: 10.1002/cncr.31337
2 Benchikh El Fegoun A, Villers A, Moreau JL, Richaud P, Rebillard $\mathrm{X}$ and Beuzeboc P: [PSA and follow-up after treatment of prostate cancer]. Prog Urol 18(3): 137-144, 2008. PMID: 18472065. DOI: 10.1016/j.purol.2007.12.010

3 Prensner JR, Rubin MA, Wei JT and Chinnaiyan AM: Beyond PSA: the next generation of prostate cancer biomarkers. Sci Transl Med 4(127): 127rv3, 2012. PMID: 22461644. DOI: 10.1126/scitranslmed.3003180

4 Wang MC, Valenzuela LA, Murphy GP and Chu TM: Purification of a human prostate specific antigen. Invest Urol 17(2): 159-163, 1979. PMID: 89106.

5 Wang MC, Papsidero LD, Kuriyama M, Valenzuela LA, Murphy GP and Chu TM: Prostate antigen: a new potential marker for prostatic cancer. Prostate 2(1): 89-96, 1981. PMID: 6169079. DOI: $10.1002 /$ pros.2990020109

6 Stenman UH, Leinonen J, Alfthan H, Rannikko S, Tuhkanen K and Alfthan O: A complex between prostate-specific antigen and alpha 1-antichymotrypsin is the major form of prostate-specific antigen in serum of patients with prostatic cancer: assay of the complex improves clinical sensitivity for cancer. Cancer Res 51(1): 222-226, 1991. PMID: 1703033.

7 Lilja H, Christensson A, Dahlén U, Matikainen MT, Nilsson O, Pettersson K and Lövgren T: Prostate-specific antigen in serum occurs predominantly in complex with alpha 1-antichymotrypsin. Clin Chem 37(9): 1618-1625, 1991. PMID: 1716536.

8 Kort SA, Martens F, Vanpoucke H, van Duijnhoven HL and Blankenstein MA: Comparison of 6 automated assays for total and free prostate-specific antigen with special reference to their reactivity toward the WHO 96/670 reference preparation. Clin Chem 52(8): 1568-1574, 2006. PMID: 16762996. DOI: 10.1373/clinchem.2006.069039

9 Catalona WJ, Partin AW, Slawin KM, Brawer MK, Flanigan RC, Patel A, Richie JP, deKernion JB, Walsh PC, Scardino PT, Lange PH, Subong EN, Parson RE, Gasior GH, Loveland KG and Southwick PC: Use of the percentage of free prostate-specific antigen to enhance differentiation of prostate cancer from benign prostatic disease: a prospective multicenter clinical trial. JAMA 279(19): 1542-1547, 1998. PMID: 9605898. DOI: 10.1001/ jama.279.19.1542

10 Vignati G and Giovanelli L: Standardization of PSA measures: a reappraisal and an experience with WHO calibration of Beckman Coulter Access Hybritech total and free PSA. Int J Biol Markers 22(4): 295-301, 2007. PMID: 18161661. DOI: $10.5301 / \mathrm{jbm} .2008 .220$

11 Blanchet $\mathrm{J}$ and Brinkmann T: The clinical impact of WHO standardization of PSA assays. Journal of Medical Biochemistry 27(2): 161-168, 2020. DOI: 10.2478/v10011-008-0010-7

12 Stamey TA: Second Stanford Conference on international standardization of prostate-specific antigen immunoassays: September 1 and 2, 1994. Urology 45(2): 173-184, 1995. PMID: 7531897. DOI: $10.1016 / 0090-4295(95) 80001-8$

13 Catalona WJ, Richie JP, Ahmann FR, Hudson MA, Scardino PT, Flanigan RC, DeKernion JB, Ratliff TL, Kavoussi LR, Dalkin BL, Waters WB, MacFarlane MT and Southwick PC: Comparison of digital rectal examination and serum prostate specific antigen in the early detection of prostate cancer: results of a multicenter clinical trial of 6,630 men. J Urol 197(2S): S200-S207, 2017. PMID: 28012755. DOI: 10.1016/j.juro.2016.10.073

14 Stephan C, Bangma C, Vignati G, Bartsch G, Lein M, Jung K, Philippe M, Semjonow A and Catalona WJ: 20-25\% lower 
concentrations of total and free prostate-specific antigen (PSA) after calibration of PSA assays to the WHO reference materials - analysis of 1098 patients in four centers. Int J Biol Markers 24(2): 65-69, 2009. PMID: 19634108. DOI: 10.5301/ jbm.2009.1349

15 Fillée C, Tombal B and Philippe M: Prostate cancer screening: clinical impact of WHO calibration of Beckman Coulter Access prostate-specific antigen assays. Clin Chem Lab Med 48(2): 285288, 2010. PMID: 20001849. DOI: 10.1515/CCLM.2010.039

16 Walsh PC: Urological oncology: prostate cancer. J Urol 184(5): 1982-1985, 2010. PMID: 22519997. DOI: 10.1016/j.juro. 2010.07.046

17 Forde JC, Marignol L, Blake O, McDermott T, Grainger R, Crowley VE and Lynch TH: Standardization of assay methods reduces variability of total PSA measurements: an Irish study. BJU Int 110(5): 644-650, 2012. PMID: 22897326. DOI: 10.1111/j.1464-410X.2011.10923.x

18 Slev PR, La'ulu SL and Roberts WL: Intermethod differences in results for total PSA, free PSA, and percentage of free PSA. Am J Clin Pathol 129(6): 952-958, 2008. PMID: 18480013. DOI: 10.1309/JYBPMFNUF6EYY9TB

19 Ross T, Ahmed K, Raison N, Challacombe B and Dasgupta P: Clarifying the PSA grey zone: The management of patients with a borderline PSA. Int J Clin Pract 70(11): 950-959, 2016. PMID: 27672001. DOI: $10.1111 /$ ijcp.12883

20 CLSI: Measurement Procedure Comparison and Bias Estimation Using Patient Samples; Approved Guideline. CLSI document EP09c. $3^{\text {rd }}$ Ed. Wayne, PA, Clinical and Laboratory Standards Institute, 2018.

21 Arcangeli CG, Smith DS, Ratliff TL and Catalona WJ: Stability of serum total and free prostate specific antigen under varying storage intervals and temperatures. J Urol 158(6): 2182-2187, 1997. PMID: 9366340. DOI: 10.1016/s0022-5347(01)68191-6

22 Simanek V, Topolcan O, Karlikova M, Dolejsova O, Fuchsova R, Kinkorova J, Slouka D and Kucera R: Stability of total prostate-specific antigen and free prostate-specific antigen after 10 years' storage. Int J Biol Markers 33(4): 463-466, 2018. PMID: 30049237. DOI: 10.1177/1724600818789414

23 Lin LI: A concordance correlation coefficient to evaluate reproducibility. Biometrics 45(1): 255-268, 1989. PMID: 2720055.
24 Bland JM and Altman DG: Statistical methods for assessing agreement between two methods of clinical measurement. Lancet 1(8476): 307-310, 1986. PMID: 2868172.

25 Stephan C, Klaas M, Müller C, Schnorr D, Loening SA and Jung $\mathrm{K}$ : Interchangeability of measurements of total and free prostatespecific antigen in serum with 5 frequently used assay combinations: an update. Clin Chem 52(1): 59-64, 2006. PMID: 16391327. DOI: $10.1373 /$ clinchem.2005.059170

26 Sturgeon CM and Ellis AR: Improving the comparability of immunoassays for prostate-specific antigen (PSA): progress and problems. Clin Chim Acta 381(1): 85-92, 2007. PMID: 17408608. DOI: 10.1016/j.cca.2007.02.015

27 Sturgeon CM: Common decision limits - The need for harmonised immunoassays. Clin Chim Acta 432: 122-126, 2014. PMID: 24291707. DOI: 10.1016/j.cca.2013.11.023

28 Sturgeon C: Standardization of tumor markers - priorities identified through external quality assessment. Scand J Clin Lab Invest Suppl 245: S94-S99, 2016. PMID: 27542005. DOI: 10.1080/00365513.2016.1210334

29 Ishibashi M: Standardization of prostate-specific antigen (PSA) assays: can interchangeability of PSA measurements be improved? Clin Chem 52(1): 1-2, 2006. PMID: 16391325. DOI: 10.1373/clinchem.2005.061325

30 Leinonen $\mathrm{J}, \mathrm{Wu} \mathrm{P}$ and Stenman UH: Epitope mapping of antibodies against prostate-specific antigen with use of peptide libraries. Clin Chem 48(12): 2208-2216, 2002. PMID: 12446478.

31 Ferraro S, Bussetti M, Rizzardi S, Braga F and Panteghini M: Verification of Harmonization of Serum Total and Free ProstateSpecific Antigen (PSA) Measurements and Implications for Medical Decisions. Clin Chem 67(3): 543-553, 2021. PMID: 33674839. DOI: $10.1093 /$ clinchem/hvaa268

Received July 29, 2021

Revised August 29, 2021

Accepted September 22, 2021 